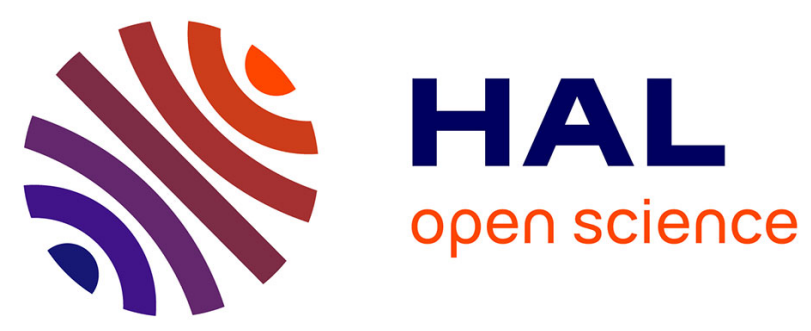

\title{
p38 mitogen activated protein kinase controls two successive-steps during the early mesodermal commitment of embryonic stem cells.
}

Emilie Barruet, Ola Hadadeh, Franck Peiretti, Valérie M. Renault, Yasmine Hadjal, Denis Bernot, Roselyne Tournaire, Didier Negre, Irène Juhan-Vague, Marie-Christine Alessi, et al.

\section{To cite this version:}

Emilie Barruet, Ola Hadadeh, Franck Peiretti, Valérie M. Renault, Yasmine Hadjal, et al.. p38 mitogen activated protein kinase controls two successive-steps during the early mesodermal commitment of embryonic stem cells.: P38 CONTROLS THE MESODERMAL COMMITMENT OF ES CELLS. Stem Cells and Development, 2011, 20 (7), pp.1233-46. 10.1089/scd.2010.0213 . inserm-00532566

\section{HAL Id: inserm-00532566 https://www.hal.inserm.fr/inserm-00532566}

Submitted on 4 Nov 2011

HAL is a multi-disciplinary open access archive for the deposit and dissemination of scientific research documents, whether they are published or not. The documents may come from teaching and research institutions in France or abroad, or from public or private research centers.
L'archive ouverte pluridisciplinaire HAL, est destinée au dépôt et à la diffusion de documents scientifiques de niveau recherche, publiés ou non, émanant des établissements d'enseignement et de recherche français ou étrangers, des laboratoires publics ou privés. 


\title{
p38 Mitogen-Activated Protein Kinase Controls Two Successive Steps During the Early Mesodermal Commitment of Embryonic Stem Cells
}

\author{
Emilie Barruet, ${ }^{1}$ Ola Hadadeh,, Franck Peiretti, ${ }^{1}$ Valérie M. Renault, ${ }^{1}$ Yasmine Hadjal, ${ }^{1}$ Denis Bernot, ${ }^{1}$ \\ Roselyne Tournaire, ${ }^{2}$ Didier Negre, ${ }^{3-5}$ Irène Juhan-Vague, ${ }^{1}$ Marie-Christine Alessi, ${ }^{1}$ and Bernard Binétruy ${ }^{1}$
}

Embryonic stem (ES) cells differentiate in vitro into all cell lineages. We previously found that the p38 mitogen activated kinase (p38MAPK) pathway controls the commitment of ES cells toward either cardiomyogenesis (p38 on) or neurogenesis (p38 off). In this study, we show that p38 $\alpha$ knock-out ES cells do not differentiate into cardiac, endothelial, smooth muscle, and skeletal muscle lineages. Reexpression of p38MAPK in these cells partially rescues their mesodermal differentiation defects and corrects the high level of spontaneous neurogenesis of knock-out cells. Wild-type ES cells were treated with a p38MAPK-specific inhibitor during the differentiation process. These experiments allowed us to identify 2 early independent successive p38MAPK functions in the formation of mesodermal lineages. Further, the first one correlates with the regulation of the expression of Brachyury, an essential mesodermal-specific transcription factor, by p38MAPK. In conclusion, by genetic and biochemical approaches, we demonstrate that p38MAPK activity is essential for the commitment of ES cell into cardiac, endothelial, smooth muscle, and skeletal muscle mesodermal lineages.

\section{Introduction}

$\mathrm{E}$ MBRYONIC STEM (ES) CELLS are pluripotent and retain the potential for unlimited proliferation. Transplantation of ES cells or their derivatives has been proposed as a future therapy for various human diseases. However, molecular mechanisms governing ES cell self-renewal and their commitment into a specific lineage are poorly understood, and their comprehension is necessary to improve the efficiency of differentiation into specific lineages.

Self-renewal of mouse ES cells is dependent on intracellular pathways initiated by the leukemia inhibitory factor (LIF), by either serum or bone morphogenetic protein 2 or 4 , and by a complex interplay between specific epigenetic processes, miRNAs, and transcription factors involved in the development of the embryo, such as Oct4, Nanog, Sox2, or FoxD3 (for review, see [1]). Removing LIF and adding appropriate differentiation reagents result in the commitment of ES cells into a variety of mature differentiated cell types, including cardiac cells, skeletal muscle cells, neurons, or adipocytes (for review, see [2,3]). ES cell differentiation can be achieved by a wide variety of experimental protocols that lack or include fetal bovine serum (FBS) and the use of specific inducers such as the potent morphogen retinoic acid (RA). The $10^{-7} \mathrm{~mol} / \mathrm{L}$ RA treatment between the second and fifth day is necessary for ES cell differentiation into neurons and adipocytes [4-6]. In contrast, ES cell differentiation in the absence of RA yields efficient differentiation to cardiomyocytes with few neurons $[4,7]$. It is very likely that different differentiation protocols and inducers will selectively activate distinct signaling pathways that turn on cell lineagespecific genetic programs to bring about the observed enrichment in differentiated cell populations. Yet, the precise molecular process of these signaling pathways controlling cell differentiation of ES cells remains poorly understood.

p38 mitogen activated kinase (p38MAPK), extracellular signal-regulated kinase (ERK), and c-Jun NH2-terminal kinase (JNK) are conserved members of signal transduction pathways activated in response to growth factors or environmental stresses [8]. ERK appears to play a major role in cell proliferation and differentiation, whereas JNK is involved in apoptosis. The p38MAPK family includes 4 members $(p 38 \alpha, p 38 \beta, p 38 \delta$, and $p 38 \gamma)$. These proteins are activated by phosphorylation in response to osmotic stress, UV, and various cytokines involved in inflammatory responses. p38MAPKs, mainly p38 $\alpha$, have been proposed to regulate

\footnotetext{
${ }^{1}$ Inserm U626, Université de la Méditerranée, Faculté de Médecine, Marseille, France.

${ }^{2}$ Inserm U624, Université de la Méditerranée, Case 915, Parc Scientifique et Technologique de Luminy, Marseille, France.

${ }^{3}$ Université de Lyon, UCB-Lyon 1, IFR128, Lyon, France.

${ }^{4}$ INSERM, U758, Lyon, France.

${ }^{5}$ Ecole Normale Supérieure de Lyon, Lyon, France.
} 
several cellular processes, such as proliferation, cell survival, and differentiation [9]. Further, p38MAPK is directly involved in the differentiation and/or survival of several cell types, including neurons, endothelial cells, and myoblasts [10-12]. However, these studies analyzed the role of p38MAPK in the terminal differentiation of established cell lines and primary cultures; therefore an early p38MAPK role in the formation of a given lineage cannot be evidence by these approaches. Deletion of the $p 38 \alpha$ gene leads to early embryonic lethality between 11.5 and 12.5 days due to erythropoiesis deficiency [13] and/or to abnormal placental development [14], demonstrating an essential role of p38MAPK in development. In this case, the early embryonic lethality impairs the unveiling of a potential role of this kinase pathway later on during development. Therefore, analysis of ES cell differentiation represents a unique experimental model to dissect p38MAPK functions from undifferentiated ES cells to well-differentiated cells.

In ES cells, p38 $\alpha$ accounts for most of p38MAPK activity because $\mathrm{p} 38 \alpha^{-1-}$ ES cells present no remaining p38MAPK activity [15]. Interestingly, we previously found that, at the opposite of wild-type (wt) ES cells, this knock-out (KO) cell line spontaneously form neurons and are impaired in cardiomyocyte formation. We found similar results by studying the effects of the highly specific p38MAPK chemical inhibitor PD169316; demonstrating that p38MAPK activity constitutes an early switch in ES cell commitment into neurogenesis (p38 off) versus cardiomyogenesis (p38 on) [16]

As this regulation takes place at the onset of the differentiation process, in this study, we investigated the role of p38MAPK in the ES cell commitment into other mesodermal lineages potentially important for cellular therapy, such as endothelial lineage, smooth muscle, and skeletal muscle. We found that p38MAPK is necessary early for these differentiations and that this requirement can be dissected into 2 independent successive steps.

\section{Materials and Methods}

\section{Differentiation of ES cells}

Mouse ES cells CGR8 [17] were grown on gelatin-coated plates, as well as the $15^{-/-}$ES cells [18] after adaptation on gelatin. $1^{-/-}$cells [18] were grown on MEF feeder cells treated with $10 \mu \mathrm{g} / \mathrm{mL}$ mitomycin $\mathrm{C}$ for $3 \mathrm{~h}$. For embryoid body (EB) formation at day $0,1 \times 10^{3}$ ES cells were aggregated in hanging drops $(20 \mu \mathrm{L})$ without LIF, as described previously [17]. For cardiomyocyte, neuron, and myotube formation, EBs were cultivated in suspension until day 7 and then plated on gelatin-coated 6-well plate as already described [16, 19]. Cardiomyocytes (beating cells) and neurons (cells with neurites) were visible at day 12 and myotubes (spontaneous contractile polynucleated myotubes) at day 26. Quantification was given as the percentage of EBs with cardiomyocytes, neurons, or myotubes. As for the endothelial and smooth muscle differentiation, EBs were plated on gelatin-coated 6-well plates or on $5 \mathrm{mg} / \mathrm{mL}$ Matrigel-coated 24-well plates (BD Biosciences) at day 3 and the media were changed every 2 days until day 12 . During EB differentiation, $10 \mu \mathrm{mol} / \mathrm{L}$ of the p38 inhibitor PD169316 (Sigma-Aldrich) was added to the culture media at different periods of time.

\section{Western blot analysis}

For p38MAPK protein analysis, EBs were lysed as previously described [17]. Samples $(30 \mu \mathrm{g})$ were separated by SDS-polyacrylamide gel electrophoresis on a 10\% gel (Invitrogen) and transferred onto polyvinylidene difluoride membranes (Millipore). Membranes were incubated with antibodies against either all p38MAPK isoforms, MAPKAPK2, MAPKAPK2phospho (Cell Signalling Technology), ERK2, or HA epitope (Santa Cruz).

\section{Immunofluorescence staining}

Differentiated EBs were washed and fixed at day 7 in 3\% paraformaldehyde for $15 \mathrm{~min}$ at room temperature. Cell membranes were permeabilized in phosphate-buffered saline (PBS) with $0.1 \%$ Triton $\mathrm{X}-100$ for $15 \mathrm{~min}$ at room temperature and incubated with a monoclonal anti-CD31/ PECAM (eBioscience), an anti-Troponin T (CT3), or an antiMHC (MF2Ds) (DSHB) in PBS $+10 \%$ FBS for $1 \mathrm{~h}$. After 3 washes in PBS, cells were incubated with anti-mouse ALEXA488 or ALEXA546 (Invitrogen) for $1 \mathrm{~h}$ at room temperature. Cell imaging was performed using a Nikon microscope Eclipse 90I. Z-stack pictures were obtained by using a Nikon Digital Sight DS-1QM camera controlled by NIS element AR software (Nikon).

\section{Flow cytometry}

EBs were dissociated into single-cell suspensions by trypsinization. Following a wash with $10 \%$ FBS/Dulbecco's modified Eagle's medium, cells were permeabilized with $0.2 \%$ Triton/PBS buffer for $10 \mathrm{~min}$ at room temperature. Cells were then stained with an $\alpha$-cardiac Troponin T (CT3) antibody or an $\alpha$ Myogenin (FD5) antibody at 1:10 dilution in 5\% FBS/PBS (DSHB) for $1 \mathrm{~h}$. Following washes with 5\%FBS/PBS, cells were incubated with an anti-mouse IgG secondary antibody conjuguated to PE (1:100 dilution in 5\% FBS/PBS; Beckman Coulter) for $30 \mathrm{~min}$ in the dark. After additional washes in PBS, cells were resuspended in $500 \mu \mathrm{L}$ PBS and analyzed on an FC500 Flow cytometer using CXP software (Beckman Coulter). For each sample, at least 5,000 cells were analyzed. Cursor for positive fluorescent cells was placed, such as $95 \%$ of events were excluded (first decade) when an isotype IgG antibody was used. Results are given as percentage corresponding to positive fluorescent cells included in the region defined by the cursor.

\section{RNA analysis}

Total RNA was prepared using trizol reagent (Invitrogen). Real-time reverse transcription-polymerase chain reaction (RT-PCR) was performed with the ABI Prism7300 (Applied BioSystems) and Taqman or Mesa Green MasterMix (Eurogentec). The relative amounts of different mRNAs were quantified by using the comparative CT method $\left(2^{-(\Delta \Delta C T)}\right)$. 36B4 was used as housekeeper transcripts and gene expressions were normalized using 36B4 RNA levels. Primer sequences are given in Supplementary Table S1 (Supplementary Data are available online at www.liebertonline.com/scd).

\section{Plasmids}

Two sequences of chromatin insulator were added to the CAGop plasmid [20] using SacI restriction sites (pCAG-op- 
Ins2X). The pcDNA3-p38 $\alpha$ vector containing the human $p 38 \alpha$ cDNA carrying an HA tag was a gift from Dr. Engelberg, Jerusalem, Israel. The pCAG-op-Ins2X-p38 $\alpha$ was generated by inserting a KpnI-KpnI fragment from the pcDNA3-p38 $\alpha$ into the pCAG-op-Ins2X.

\section{Generation of ES cell lines}

The $1^{-/-}$and $15^{-/-}$ES cell lines were cotransfected with the pGK-HygroR and pCAG-op-Ins2X-p38 $\alpha$, at a 10:1 ratio, using the FuGene HD transfection system (Roche Molecular Biochemicals) according to the manufacturer's protocol, and selected in $100 \mu \mathrm{g} / \mathrm{mL}$ hygromycin (Invitrogen) to generate p38 $8^{-1-}$ ES cell clones expressing exogenous p38 $\alpha$.

In the case of $1^{-/-}$cell line, transfection was realized onto mitomycin C-treated MEF feeder cells. Stable, hygromycinresistant MEF cells were obtained by transduction with the CHC vector, an MLV retrovirus vector coding the hph cDNA [21] using an MOI of $6 \mathrm{UI} /$ cell, followed by hygromycin selection $(100 \mu \mathrm{g} / \mathrm{mL})$. Moloney leukemia virus (MLV)-based vector was generated by transient transfection of 293T cells as previously described [22].

\section{Statistical analyses}

All experiments were performed at least 3 times. All data are expressed as the mean \pm standard error of the mean. Treatments were compared with their respective controls and significant differences among the groups were determined using unpaired Student's $t$-test. A $P$-value of $<0.05$ was taken as an indication of statistical significance.

\section{Results \\ p38 $\alpha^{-/-}$ES cells do not differentiate into endothelial, smooth muscular, and skeletal muscular mesodermal lineages}

In addition to cardiomyogenesis and neurogenesis, endothelial and smooth muscle differentiations are among the earliest lineages to arise, both in vivo, during embryo formation, and in vitro, during ES cell differentiation [23]. In the present study, we compared 2 p38 $\alpha$-homozygote KO ES cell lines [18], clones $1^{-/-}$and $15^{-/-}$, to the standard CGR8 ES cell line. Undifferentiated cells were induced to differentiate by the technique of EB formation [16] and RNAs were extracted by day 12 or 26 and gene expression for specific cell lineage markers was evaluated by real-time RT-PCR. Similar to what we previously found, spontaneous cardiomyogenesis was drastically impaired in these $\mathrm{KO}$ cells when compared with wt CGR8 cells. At day 12 of differentiation, cardiac phenotype, quantified by both the percentage of EB outgrowths with contractile cells and expression of the cardiac specific markers Nkx2.5 and GATA-4, was significantly reduced in the $2 \mathrm{KO}$ cell lines when compared with wt cells (Supplementary Fig. 1A-C). In wt CGR8 cells, neuron formation by day 12 was not spontaneous and was strictly dependent on an RA treatment between days 3 and 5 [16]. In contrast, $35 \%-50 \%$ of EBs of the cell line $1^{-/-}$form neurons by day 12 of the differentiation protocol, with or without RA treatment, and express high levels of the neuronal specific marker MAP2, measured by real-time RT-PCR (Supplementary Fig. 2A, B and Fig. 5). Surprisingly, the $15^{-/-}$cell line does not show any neuronal differentiation tendency, even after RA treatment (Supplementary Fig. 2A, B). One could hypothesize that, in this cell line, neurogenesis is inhibited by an unknown molecular event, independent of $\mathrm{KO}$ of the $p 38 \alpha$ gene.

To test endothelial differentiation we used a previously established protocol [24]. Endothelial phenotype was characterized by anti-PECAM (also known as CD31) immunofluorescence (Fig. 1A, left column) and formation of typical vessel-like structures on Matrigel (Fig. 1A, right column). Endothelial differentiation was also analyzed by measuring the expression levels of endothelial-specific markers. mRNA expression profiles of Flk-1 and Tie2 genes show a sharp and robust increase after day 3 or 5 of differentiation, respectively, and an increasing Flk-1 expression until day 12, whereas Tie-2 expression diminishes after day 7 (Fig. 1B, C). The expressions of the endothelial markers PECAM and vWF show biphasic expression profiles, decreasing to low levels from day 0 to day 3 , and then a progressive increase from day 3 to day 7 (Supplementary Fig. S1D, E). The PECAM profile is very similar to what has been already described in other ES cell lines [25] — the expression level found in undifferentiated cells was not correlated to endothelial differentiation. When induced to differentiate on either gelatin or Matrigel from day $3, \mathrm{p}^{-/-}$cells show almost no vessel-like structures (Fig. 1A); this lack of differentiation was characterized by the blockade of gene expression of the Flk-1, Tie-2, vWF, and CD31 markers (Fig. 1B, C and Supplementary Fig. S1D, E). These results present a discrepancy with those published by Guo et al., who showed that p38 $\alpha$ KO ES cells can differentiate toward endothelial cells [26]. However, in this study, quantification of expression of endothelial markers was performed in a different KO ES cell line and, more importantly, only 2 markers were tested, one (PECAM) presenting no variation between $\mathrm{KO}$ and wt cells, whereas the other (VEcad) was found significantly downregulated in $\mathrm{KO}$ cells, suggesting an endothelial defect of these cells.

In parallel to endothelial cells, these culture conditions lead also, in the same Petri dishes, to the differentiation of vascular smooth muscle cells, which participate in the formation of vessel-like structures $[24,27,28]$. Our culture conditions are also permissive for this differentiation, as indicated by the high level of gene expression in wt ES cells at days 7-12 of the specific marker $\alpha$-smooth muscle actin (Fig. 1D). Similar to endothelial differentiation, formation of the smooth muscle cell lineage was also impaired in p38 $\alpha \mathrm{KO}$ cells (Fig. 1D).

Our results suggest that, in addition to cardiomyogenesis, the p38MAPK pathway is required for the formation of endothelial and smooth muscle cell lineages.

We then analyzed the potential role of p38MAPK in mesodermal lineages formed later on during development, such as skeletal myogenesis. After 26 days of induction, wt ES cells form spontaneous contractile myotubes (Supplementary Fig. S1F) and express specific skeletal muscular genes such as Myosin Heavy Chain 1 (MyH1; Fig. 1E) and Myogenin (Supplementary Fig. S1G). In contrast, both the 2 p38 $\alpha$ KO cell lines were impaired in their skeletal myogenic capacities, reduced number of EB-forming myotubes and reduced expression of markers (Fig. 1E and Supplementary Fig. S1F, G). These results demonstrate that the p38MAPK pathway is also required for formation of skeletal muscle, a late-forming mesodermal lineage. 
FIG. 1. Wild-type but not p38 $\alpha^{-/-}$ES cells differentiate toward endothelial cells, smooth muscle cells, or skeletal myotubes. (A) EBs from $1^{-/-}$and $15^{-/-}$, KO for p38 $\alpha$, and wt CGR8 ES cells were plated on gelatin (left column) or Matrigel (right column) at day 3 of differentiation. Cells were either analyzed by immunofluorescence using anti-PECAM antibodies (400x magnification; left column) or photographed using a phase-contrast microscope (right column) at day 7 of differentiation (magnification was $100 \times$ for wt cells and 200x for p38 KO cells). Representative results are shown; arrows indicate the vessel-like structures formed on Matrigel. In parallel similar experiments, for endothelial and smooth muscle differentiations, mRNAs were extracted at days 3, 5, 7, and 12 and analyzed by realtime RT-PCR for the expression of endothelial markers, Flk-1 (B) and Tie-2 (C), and the smooth muscle cell marker alpha-SMA (D). For skeletal myogenesis analysis, the expression of the skeletal myogenic marker $\mathrm{MyH} 1$ was evaluated by day 26 for each cell line (E). Results are expressed in arbitrary units, with the values of wt CGR8 at day 0 taken as 1 , and are the means \pm SEM of at least 3 independent experiments. Significance between wt and $\mathrm{KO}$ cells is given as ${ }^{*} P<0.05$ and ${ }^{* *} P<0.01$. ES, embryonic stem; EB, embryoid body; wt, wild-type; KO, knock-out; alpha-SMA, alpha-smooth muscle actin; RT-PCR, reverse transcription-polymerase chain reaction; MyH1, myosin heavy chain-1; SEM, standard error of the mean. Color images available online at www.liebertonline.com/scd

\section{Construction of $p 38 \alpha K O$ cell derivatives expressing exogenous $p 38$ proteins}

To demonstrate that mesodermal differentiation defects of $p 38 \alpha^{-/-}$cell lines are due to the KO of p38, we reexpressed p38MAPK in these $\mathrm{KO}$ cells. We used an expression vector for an HA-tagged p38 $\alpha$ cDNA under the control of the synthetic CAG promoter, known to be very potent in ES cells before and upon differentiation [20,29]. We isolated and analyzed p38-reexpressing ES derivatives from $\mathrm{KO}$ cell lines: clone R1-1 for the cell line $1^{-/-}$and R15-1 and R15-2 for the cell line $15^{-/-}$. In the presence of LIF, all these cell lines display an ES morphology (data not shown) and express levels of Oct4 and Nanog, major specific genes of pluripotency, similar to wt and p38 $\alpha$ KO ES cells (Supplementary Fig. S3A, B). We first checked the persistence of transgene expression during the differentiation process by real-time RT-PCR. As shown in Supplementary Fig. S3C, all cell lines conserve their p38 cDNA transgene expression from day 0 to day 26. Protein expression levels were analyzed by western blots with either anti-p38 total ( $\alpha$-p38tot) or anti-HA antibodies and anti-ERK antibodies as control (Fig. 2). Reex- 


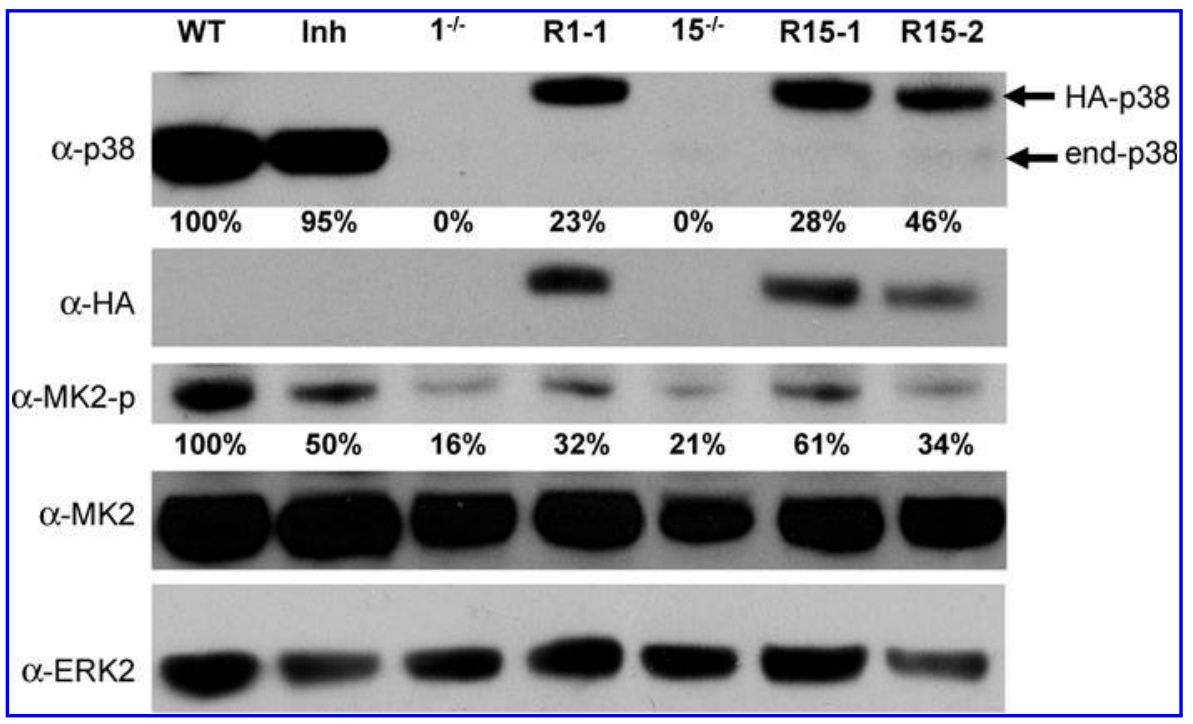
equivalent ERK expression, and expressed as percentage of the endogenous p38 expression found in CGR8 wt cells. PhosphoMAPKAP-K2-protein expression signals were quantified, corrected for equivalent total MAPKAP-K2 expression, and expressed as percentage of the expression found in CGR8 wt cells. $\alpha$-HA, $\alpha$-hemaglutinin antigen; MAPKAP-K2, MAPK, mitogen activated protein kinase-activated protein kinase-2; $\alpha$-ERK2, $\alpha$-extracellular signal-regulated kinase 2.

pressing cell lines present only partial restoration of wt endogenous p38 protein levels, between $23 \%$ and $46 \%$ of levels present in wt cells, at day 4 of differentiation (Fig. 2); similar results were obtained at days 0,12 (data not shown), and 20 (Supplementary Fig. S3D). As a functional test for investigating the restored activity of the p38MAPK pathway, we analyzed the phosphorylation status of a known direct p38MAPK target: the MAPK activated protein kinase-2 (MAPKAP-K2) [9]. Western blots using anti-MAPKAP-K2 total or phosphorylated proteins demonstrated that p38MAPK KO cells display the remaining proportion of phosphorylated MAPKAP-K2 proteins comprised between $16 \%$ and $21 \%$ of levels in wt cells (Fig. 2). These low but not null levels indicate that, although the phosphorylation of MAPKAP-K2 protein is a good indication of $\alpha$-p38MAPK activity, this protein can be targeted by other kinases. We found that incubation of wt cells with the p38MAPK inhibitor leads to only 50\% reduction in MAPKAP-K2 phosphorylation (Fig. 2); this result could also be due to alternative pathways phosphorylating this protein. Interestingly, reexpressing cell lines present intermediate levels (32\%-61\%) between $\mathrm{KO}$ and wt, compatible with their partial restoration of p38MAPK expression (Fig. 2).

\section{Reexpression of p38 protein in p38 $\alpha \mathrm{KO}$ cell lines rescues their defects in mesodermal differentiation}

We then analyzed the reexpressing cell lines for their differentiation capacities toward the cardiac, endothelial, smooth muscular, skeletal muscular, and neuronal lineages.

Cardiomyogenesis was evaluated by the percentage of EBs with beating cells (Fig. 3A), Gata-4 (Fig. 3B) and Nkx2.5 expressions (Supplementary Fig. S4A), and flow cytometry with anti-Troponin T antibodies (Fig. 3C and Supplementary Fig. S4C) at day 12. Remarkably, cardiomyocytes formation was significantly, but partially, restored in the 3 reexpressing

FIG. 2. Molecular characterization of p38 $\alpha \mathrm{KO}$ cell derivatives partially reexpressing $\mathrm{p} 38 \alpha$ protein. $\mathrm{p} 38 \alpha$ protein expression at day 4 of differentiation of various ES cell lines was analyzed by western blotting with pan-p38 ( $\alpha$-p38), $\alpha-\mathrm{HA}, \alpha-$ phosphoMAPKAP-K2 ( $\alpha-\mathrm{MK} 2-\mathrm{p})$, and $\alpha$-MAPKAP-K2 total $(\alpha-\mathrm{MK} 2)$ antibodies. Membranes were reprobed with $\alpha$-ERK2 antibodies as loading control. Migrations of endogenous p38 and HA-p38 proteins are indicated (right-hand side). Analysis of wild-type CGR8 cells (WT), treated (Inh) or not with the p38 specific inhibitor, the $1^{-/-}$and $15^{-/-}$ p38 KO cell lines, and their derivatives R1-1 and R15-1 and -2 is shown. p38 protein expression signals obtained with pan-p38 antibodies were quantified, corrected for 


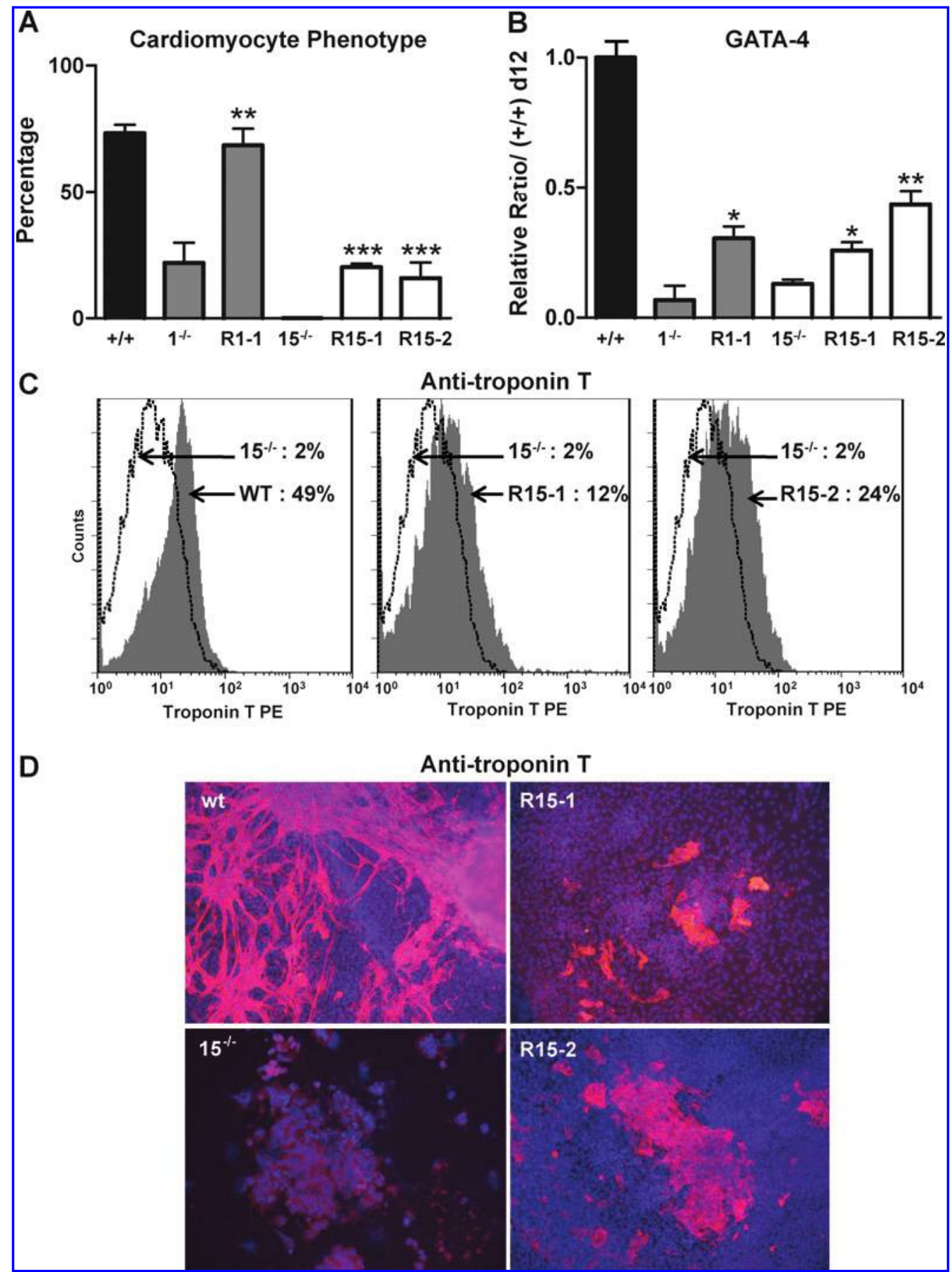

FIG. 3. Reexpression of p38 protein in KO cell lines partially rescues their defects in cardiomyogenesis. EBs from wt CGR8, $1^{-/-}, \mathrm{R} 1-1,15^{-/-}, \mathrm{R} 15-1$, and R15-2 ES cells were plated on gelatin at day 7 of differentiation and analyzed at day 12. (A) Cardiomyocyte phenotype was expressed as the percentage of EBs with beating cell areas. Values are expressed as means of at least 3 independent experiments \pm SEM. (B) mRNAs were analyzed by real-time RT-PCR for expression of the specific cardiac marker GATA-4. Results are expressed in arbitrary units, with the values of wt CGR8 at day 12 taken as 1 , and are the means \pm SEM of at least 3 independent experiments. Significance between $\mathrm{KO}$ and reexpressing cells is given as ${ }^{*} P<0.05$, ${ }^{* *} P<0.01$, and ${ }^{* *} P<0.001$. (C) Differentiated cells at day 12 were analyzed by flow cytometry analysis of Troponin T. A histogram representative of 3 independent experiments is shown. For each experiment, control value (irrelevant) was determined as no more than 5\% of positivity. (D) Differentiated cells at day 12 were analyzed by immunofluorescence using anti-Troponin $\mathrm{T}$ antibodies (magnification: 100x). Nuclei were stained with DAPI. DAPI, 4',6-diamidino-2-phenylindole. Color images available online at www.liebertonline.com/scd 
molecular characteristics could participate in the differentiation defects of $\mathrm{KO}$ cell lines. One can hypothesize that these differences could be due to genetic instability of $\mathrm{KO}$ cells leading to variability in their biological responses.

\section{p38MAPK activity is required for 2 early successive steps in mesodermal commitment of ES cells}

To bypass these potential genetic differences, we analyzed the role of p38MAPK by directly inhibiting its activity in differentiating wt ES cells with the specific chemical inhibitor PD169316. Further, inhibitor treatment of differentiating ES cells from day 3 to day 5 blocks the spontaneous peak of p38MAPK activity observed at that step [16]. The inhibitor was applied in 3 different conditions: (i) all the time of differentiation, from day 0 to day 7,12 , or $26(\mathrm{~d} 0-\mathrm{d} 7, \mathrm{~d} 0-12$, d0-d26, depending of the lineage analyzed); (ii) only from day 0 to day 3 (d0-d3); (iii) from day 3 to day 5 (d3-d5) (Fig. 6A). We focused our study on the $\mathrm{d} 0-\mathrm{d} 5$ period because inhibition of p38MAPK after day 5 has no effect (Supplementary Fig. S6).

Cardiomyogenesis of ES cells is completely inhibited by either the $\mathrm{d} 0-\mathrm{d} 12$ or $\mathrm{d} 3-\mathrm{d} 5$ treatment (Fig. 6B-E and Supplementary Fig. S7A). This inhibition was similar to what was observed in the $1^{-/-}$and $15^{-/-} \mathrm{KO}$ cell lines. In contrast, the $\mathrm{d} 0-\mathrm{d} 3$ treatment has a very modest effect, reducing the percentage of EBs with beating cells at day 12 from $75 \%$ in control treated cells to $40 \%$ and without any effect on gene expression of cardiac markers. Therefore, the major effect on cardiomyogenesis of inhibition of p38MAPK is restricted to the $\mathrm{d} 3-\mathrm{d} 5$ period, coincidental to the spontaneous peak of p38 kinase activity.

We then analyzed the effect of the p38 inhibitor on ES endothelial and smooth muscle differentiation by day 7 . In contrast to that observed for cardiomyogenesis, the 3 different treatments were equally efficient to completely block the expression of endothelial and smooth muscle markers (Fig. 6F, G and Supplementary Fig. S7B).

Similar to endothelial and smooth muscle cell formation, we found that wt ES cells require a continuous p38MAPK activity between days 0 and 5 to differentiate, latter on, into the skeletal myogenic lineage. The 3 different p38 inhibitor treatments completely inhibit the formation of contractile myotubes and expression of myogenic markers, evaluated at day 26 (Fig. 7 and Supplementary Fig. S7C).

\section{p38MAPK activity controls expression of the mesodermal master gene Brachyury}

In the mouse embryo, mesoderm is generated from the epiblast through the process of gastrulation, which is initiated at day 6.5 of gestation. The transcription factor-encoding Brachyury gene is specifically expressed in nascent mesoderm and downregulated as these cells differentiate into skeletal muscle, cardiac muscle, blood, and endothelium. In vivo studies have demonstrated the importance of Brachyury in regulating cell fate decisions. Brachyury ${ }^{-/-}$mice die shortly after gastrulation and display several mesodermal abnormalities [30]. However, the role of this gene in ES cell differentiation in vitro is unknown. Because our results demonstrate the early requirement of p38MAPK in mesodermal commitment of ES cells, we hypothesized that this effect could be mediated by regulation of Brachyury.
Brachyury gene expression was investigated between days 0 and 7 of differentiation of $w t, K O$, and $\mathrm{p} 38 \alpha$ reexpressing ES cells. As expected, expression of this gene is very low in wt undifferentiated ES cells. Expression profile during EB differentiation shows a peak of expression, centered at day 3 , of 32-fold the level at day 0 , going down to the basal level of undifferentiated cells by day 5 and staying low until day 7 (Fig. 8). This profile is identical to the one described in the work by Fehling et al. [31], using another wt ES cell line, and is compatible with an important function for this gene in ES cell commitment toward mesoderm lineages. In contrast to wt cells, p38 $\alpha \mathrm{KO}$ ES cells present no peak of Brachyury expression (Fig. 8A, B). This result is in line with the work of Duval et al. [32], who found that Brachyury gene expression is under the control of p38MAPK pathway. Our results indicate that there is a correlation between mesodermal defects of $\mathrm{KO}$ cells and low levels of Brachyury expression. However, both $1^{-/-}$and $15^{-/-}$reexpressing derivatives do not recapitulate the Brachyury expression profile of wild-type ES cells, expressing Brachyury levels slightly different to $\mathrm{KO}$ cells only after day 4 (Fig. 8A, B). Therefore, these results indicate that the restoration of mesodermal differentiation capacities displayed by reexpressing cells cannot be explained by a rescue of Brachyury expression.

To precisely understand the role of p38MAPK in the regulation of Brachyury gene expression, we then analyzed the effect of the p38 inhibitor treatment on wt ES cells during differentiation (Fig. 8C). The $\mathrm{d} 0-\mathrm{d} 7$ treatment completely blocks the expression of this gene, recapitulating the effect of the genetic $\mathrm{KO}$ and showing a correlation between Brachyury inhibition and blockade of mesodermal differentiation. In contrast, the $\mathrm{d} 3 \mathrm{-} \mathrm{d} 5$ treatment has no effect on Brachyury, leaving the peak of expression unchanged, centered at day 3 . Importantly, because this treatment is as efficient as the $\mathrm{d} 0-\mathrm{d} 7$ in inhibiting mesodermal differentiation (Fig. 7), this result demonstrates that $\mathrm{p} 38 \mathrm{MAPK}$ can regulate the formation of mesodermal lineages independently of Brachyury regulation. Surprisingly, the $\mathrm{d} 0-\mathrm{d} 3$ treatment blocks Brachyury expression until day 3 , but then its expression increases and peaks at day 5 before going down by day 7 . This treatment blocks the formation of endothelial and skeletal muscular lineages, leaving cardiomyogenesis almost unchanged (Fig. 7); this indicates that cardiac cells can be formed even if the peak of Brachyury expression at day 3 is absent.

\section{Discussion}

By genetic and biochemical approaches we previously described a role of p38MAPK as an early switch of ES cell commitment into cardiomyocytes or neurons [16]. Either gene deletion or specific inhibition of the peak of p38MAPK activity, observed between days 3 and 5 during ES cell differentiation, partially mimicked the cardiomyogenesis inhibition by $10^{-7} \mathrm{~mol} / \mathrm{L}$ RA treatment. In the present study, we extended this observation to the endothelial, smooth muscle, and skeletal muscle lineages and found that the p38MAPK requirement can be dissected into 2 successive steps during the differentiation process, one between days 0 and 3 and the second between days 3 and 5 . We found that the first step correlates with the p38MAPK regulation of Brachyury gene expression. 

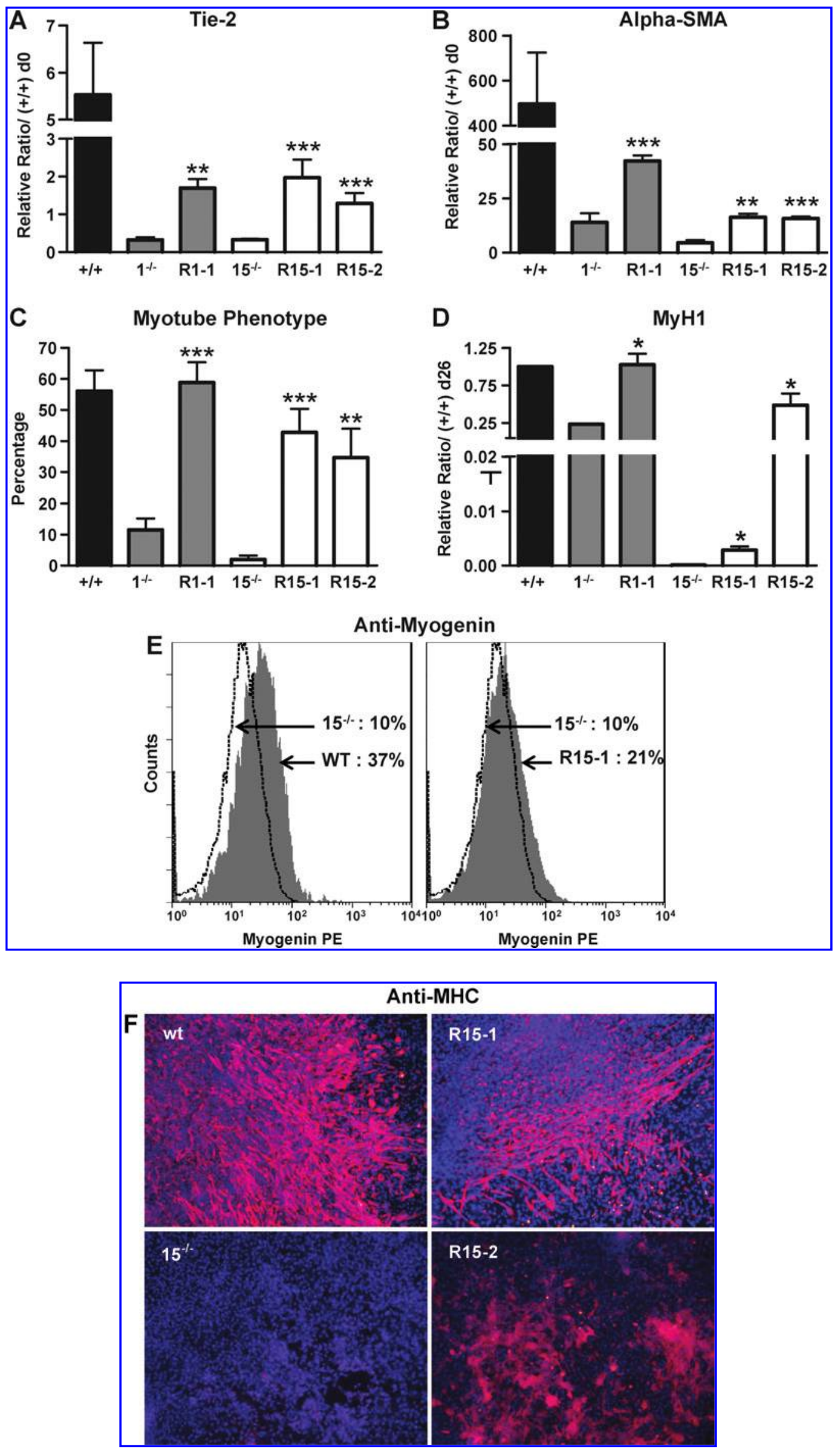


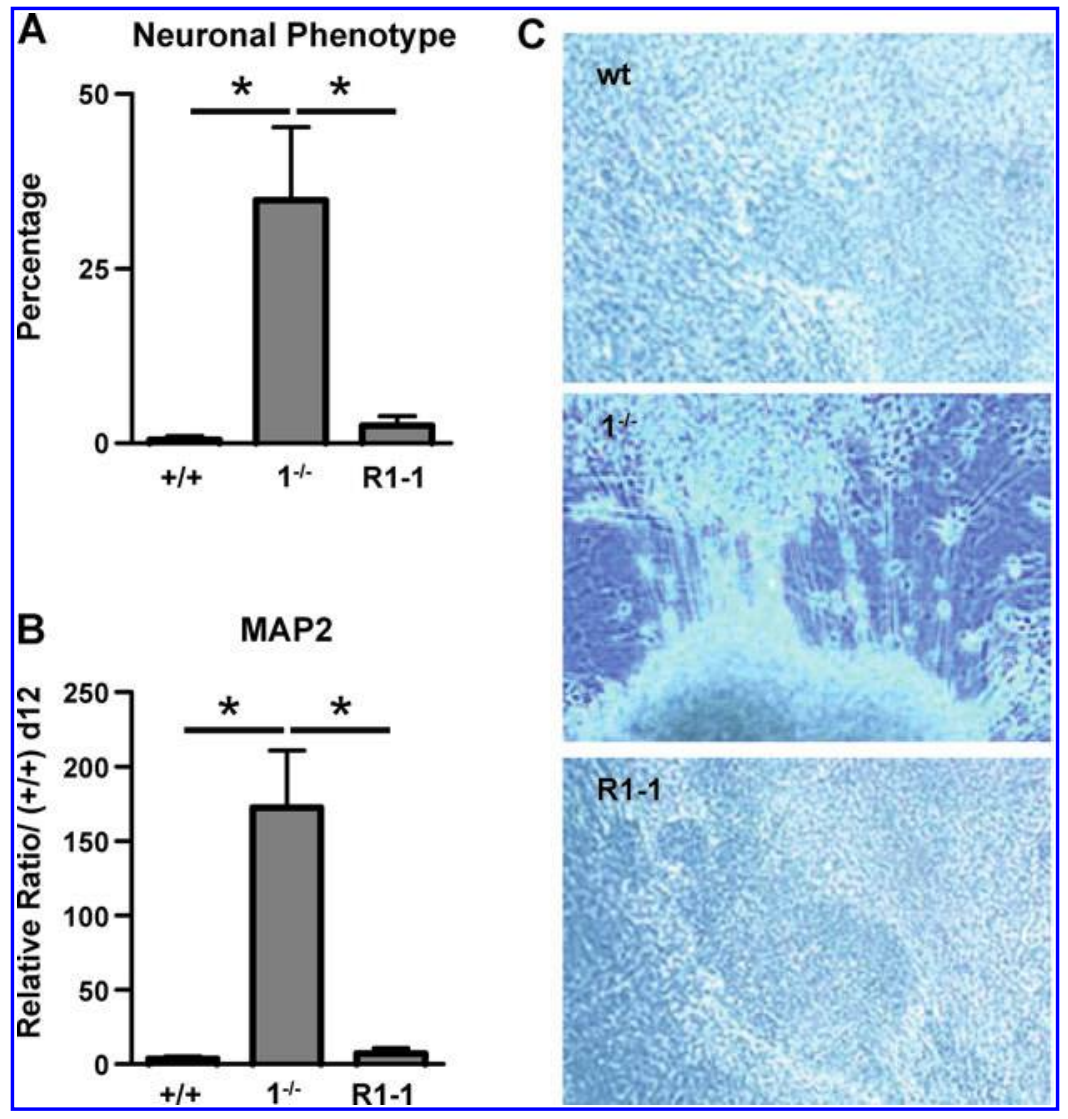

FIG. 5. Reexpression of p38 protein in $\mathrm{KO}$ cell lines inhibits their spontaneous neurogenesis. EBs from wt CGR8, $1^{-/-}$, and R1-1 ES cells were plated on gelatin at day 7 and analyzed at day 12. (A) Neuronal phenotype was expressed as the percentage of EBs with neurons in outgrowths (means $\pm S E M$ of at least 3 independent experiments). (B) mRNAs were extracted at day 12 and analyzed by real-time RT-PCR for expression of the specific neuronal marker MAP2. Results are expressed in arbitrary units, with the values of wt CGR8 at day 12 taken as 1, and are the means \pm SEM of at least 3 independent experiments. Significance is given as ${ }^{*} P<0.05$. (C) Differentiated cells at day 12 were photographed using a phase-contrast microscope (magnification was 100x for upper and lower panels and $200 \times$ for middle panel). Color images available online at www.liebertonline .com/scd

A role for $\mathrm{p} 38 \alpha$ in various aspects of cardiomyogenesis, including the regulation of cardiomyocyte differentiation, apoptosis, and hypertrophy, has been described [33-35]. Interestingly, p38 $\alpha^{-7}$ embryos present a massive reduction of the myocardiac muscle attributed to a defect in placental development [14]. By analysis of both p38 $\alpha$ KO ES cells and effects of biochemical inhibition of the pathway, we demonstrate that p38MAPK is required for the cardiomyogenesis of ES cells. Moreover, successive treatments of ES cells with the p38 inhibitor show that the major effect of inhibition of p38MAPK kinase activity on this lineage is evidenced during the $\mathrm{d} 3-\mathrm{d} 5$ period.

In contrast to our results, a recent work described an enhanced cardiomyogenesis of human ES cells by a small molecular inhibitor of p38 MAPK [36]. This apparent discrepancy could be due to different experimental param- eters between the 2 studies: 2 different cellular models (human ES cells vs. mouse ES cells); different inhibitors (SB203580 vs. PD169316), which are known to differently affect ES cell differentiation [32]; and importantly, in human ES cells these effects are concentration dependent, with an inhibitory effect at high concentrations, similar to what we found in mouse ES cells.

Circulating endothelial precursor cells provide an endogenous repair mechanism to counteract ongoing risk factorinduced endothelial injury and to replace dysfunctional endothelium [37]. p38MAPK has been involved in both the control of endothelial precursor cell proliferation [38] and the migration of mature endothelial cells [11]. Smooth muscle cells are important contributors to blood vessel integrity. Our study demonstrates that p38MAPK is crucial early on during the differentiation process of ES cells toward the endothelial

FIG. 4. Reexpression of p38 protein in $\mathrm{KO}$ cell lines partially rescues their endothelial, smooth muscle, and skeletal muscle cell defects. EBs from wt CGR8, $1^{-/-}$, R1-1, 15 $5^{-/}$, R15-1, and R15-2 ES cells were plated on gelatin at day 3 for endothelial or smooth muscle cell differentiation or at day 7 for skeletal myogenesis and analyzed at day 7 for endothelial and smooth muscle cells or at day 26 for skeletal myogenesis. mRNAs at day 7 were analyzed by real-time RT-PCR for expression of the endothelial marker Tie-2 (A) and the smooth muscle marker $\alpha$-SMA (B). (C) The ratio of EBs with spontaneous contractile myotubes was evaluated by day 26 for each cell line; at least 50 different EBs per cell line were counted. Histogram shows the means \pm SEM of 3 independent experiments. (D) mRNAs were analyzed by real-time RT-PCR for expression of the specific skeletal muscle marker MyH1. Results are expressed in arbitrary units, with the values of wt CGR8 at day 0 (A, B) or day 26 (D) taken as 1, and are the means \pm SEM of at least 3 independent experiments. Significance between KO and reexpressing cells is given as ${ }^{*} P<0.05,{ }^{* *} P<0.01$, and ${ }^{* * *} P<0.001$. (E) Differentiated cells at day 12 were analyzed by flow cytometry analysis of Myogenin. A histogram representative of 3 independent experiments is shown. For each experiment, control value (irrelevant) was determined as no more than 5\% of positivity. (F) Differentiated cells at day 12 were analyzed by immunofluorescence using anti-MHC antibodies (magnification: 100x). Nuclei were stained with DAPI. Color images available online at www .liebertonline.com/scd 
and smooth muscle lineages. In contrast to cardiomyogenesis, this signal transduction pathway is required continuously between days 0 and 5 for the ES commitment of these lineages. Our data are consistent with the p38MAPK pathway constituting an important potential player in vessel reconstruction from ES cells.

To explain the role of P38MAPK in ES cell differentiation toward cardiac, endothelial, and smooth muscle cells, one simple hypothesis would be that this pathway targets a precursor common to these lineages. For example, such precursor could be located in defined structures that could be represented in vivo by the hemangioblast, which has been defined as the early embryonic structure capable to generate both hematopoietic and vascular lineages [39,40]. This structure is molecularly characterized by the coexpression, during a limited period of time, of Brachyury and Flk-1

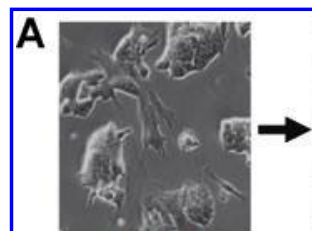

ES cells

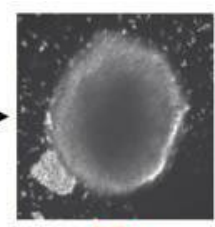

EBs

B

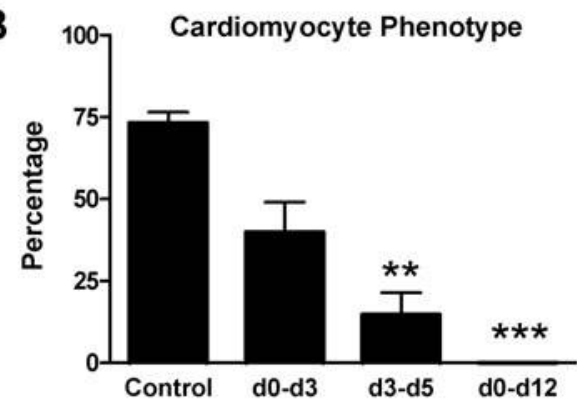

D

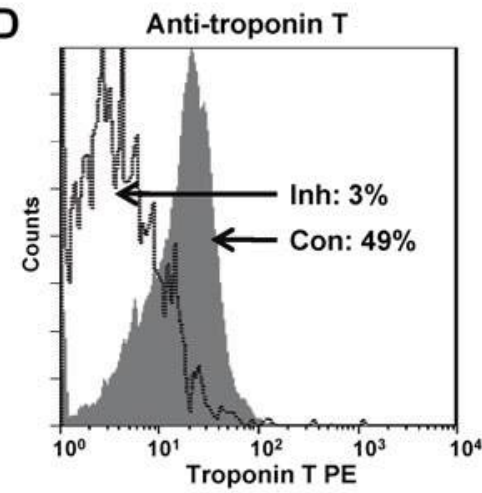

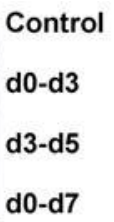

-

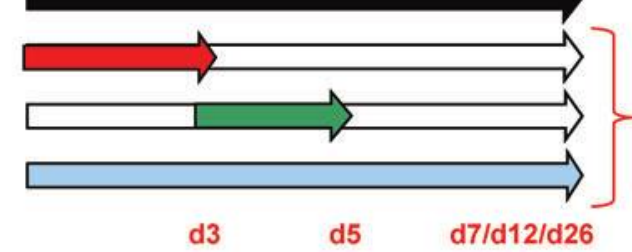

C

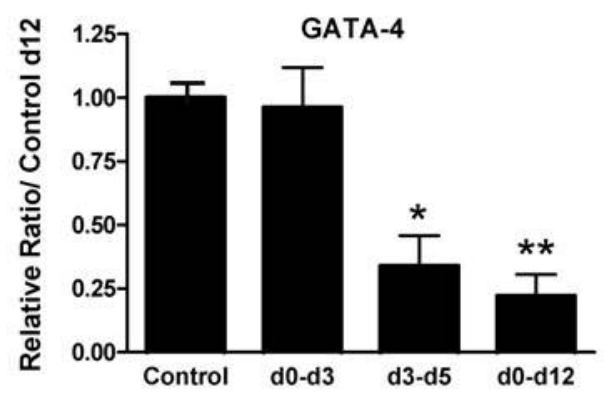

treatment with $10 \mu \mathrm{M}$ of the $\mathrm{p} 38$ INH

(PD169316)

E
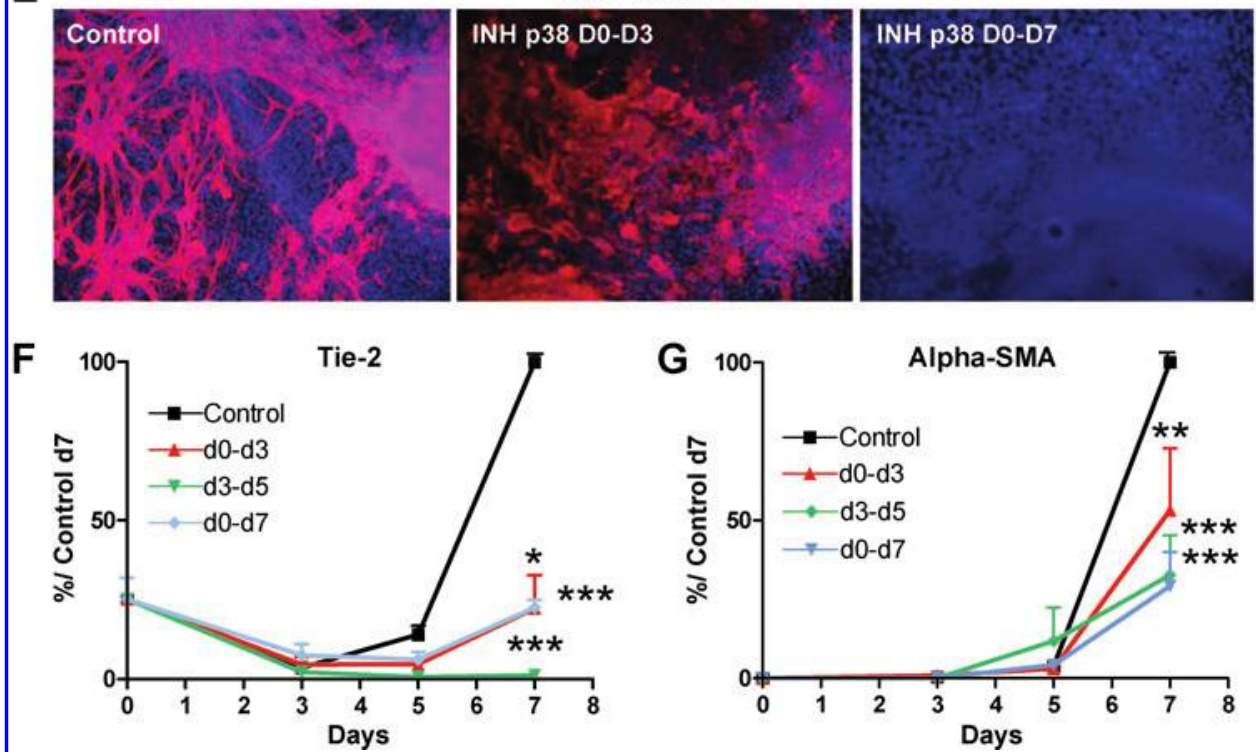


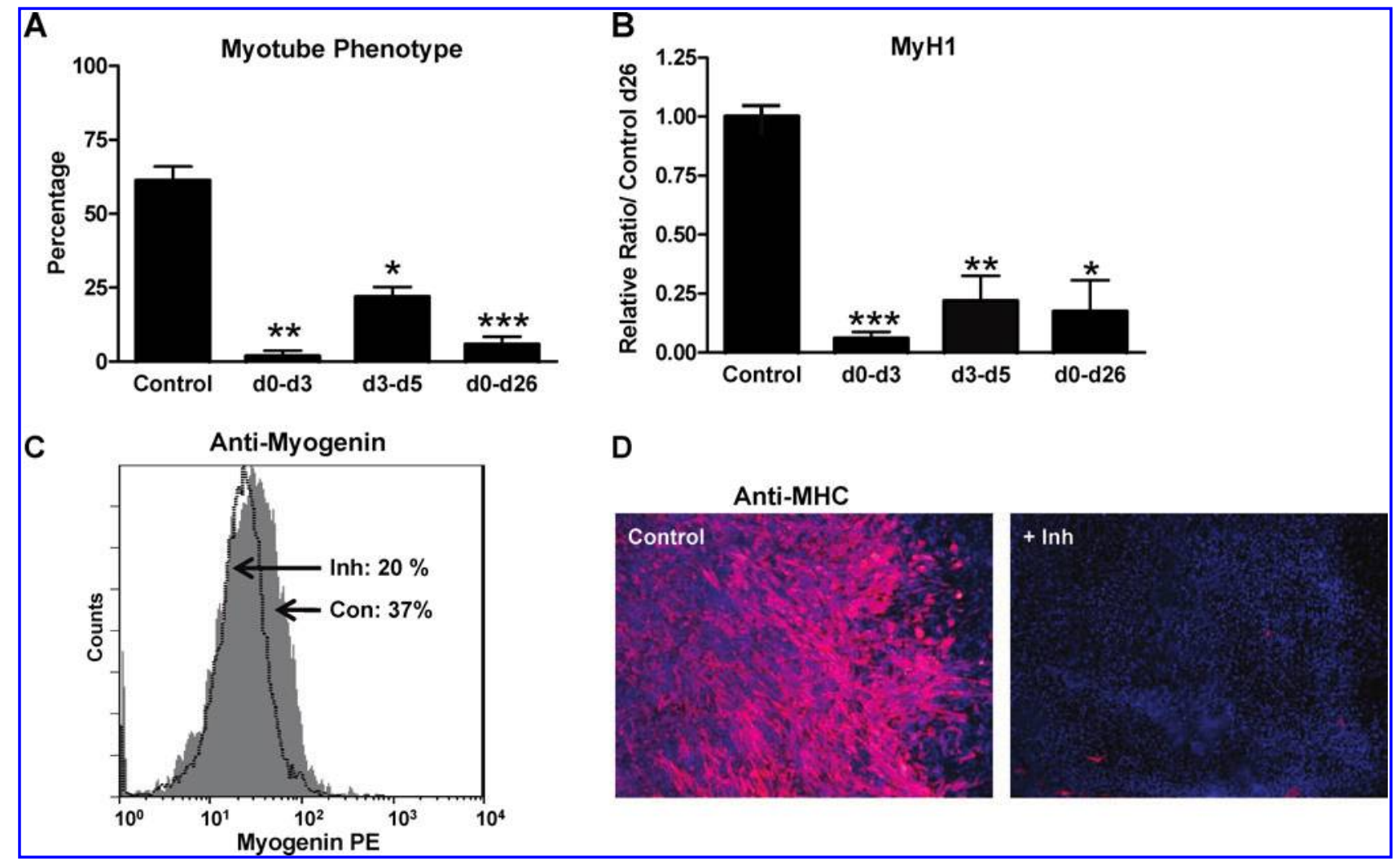

FIG. 7. p38MAPK activity is required for 2 early successive steps in skeletal myogenesis of ES cells. EBs from wt CGR8 ES cells were differentiated in the presence or absence of PD169316 for different periods as indicated schematically in Fig. 6A. EBs were plated at day 7 and analyzed at day 26 of differentiation. (A) The ratio of differentiated EBs with spontaneous contractile myotubes was evaluated for each cell line; at least 50 different EBs per cell line were counted. Histogram shows the means \pm SEM of 3 independent experiments. (B) In these experiments, mRNAs were extracted at day 26 and analyzed by real-time RT-PCR for expression of the specific skeletal muscle marker MyH1. Results are expressed in arbitrary units, with the values of wt CGR8 at day 26 taken as 1, and are the means \pm SEM of at least 3 independent experiments. Significance between control and treated cells is given as ${ }^{*} P<0.05,{ }^{* *} P<0.01$, and ${ }^{* * *} P<0.001$. (C), Differentiated cells at day 12 were analyzed by flow cytometry analysis of Myogenin. A histogram representative of 3 independent experiments is shown. For each experiment, control value (irrelevant) was determined as no more than $5 \%$ of positivity. (D) Differentiated cells at day 12 were analyzed by immunofluorescence using anti-MHC antibodies (magnification: 100x). Nuclei were stained with DAPI. Color images available online at www.liebertonline.com/scd

genes. Interestingly, we also found these 2 genes to be regulated by p38MAPK in our cellular model. Whether Brachyury and Flk-1 are the only p38MAPK targets required for the control of hemangioblast formation leading to endothelial and smooth muscle lineages necessitate further investigations. However, the fact that cardiomyogenesis presents sensitivity to the p38 inhibitor different from the other lineages suggests the existence of several distinct precursors. Because the d3-d5 treatment with the inhibitor affects differentiation without changing Brachyury gene expression, we hypothesize that, at this precise step, p38MAPK regulates critical unknown mesodermal regulators.

FIG. 6. p38MAPK activity is required for 2 early successive steps in mesodermal commitment of ES cells. EBs from wt CGR8 ES cells were differentiated in the presence or absence of PD169316 for different periods as indicated schematically in (A). For cardiomyogenesis, EBs were plated at day 7 and analyzed at day 12 of differentiation. Cardiomyocyte phenotype was expressed as the percentage of EBs with beating cell areas (means \pm SEM of at least 3 independent experiments) (B). In these experiments, mRNAs were extracted at day 12 and analyzed by real-time RT-PCR for expression of the specific cardiac marker GATA-4 (C). Results are expressed in arbitrary units, with the values of control cells at day 12 taken as 1 , and are the means \pm SEM of at least 3 independent experiments. Significance between control and treated cells is given as ${ }^{*} P<0.05$, ${ }^{* *} P<0.01$, and ${ }^{* * *} P<0.001$. (D) Differentiated cells at day 12 were analyzed by flow cytometry analysis of Troponin T. A histogram representative of 3 independent experiments is shown. For each experiment, control value (irrelevant) was determined as no more than 5\% of positivity. (E) Differentiated cells at day 12 were analyzed by immunofluorescence using anti-Troponin T antibodies (magnification: 100x). Nuclei were stained with DAPI. For endothelial and smooth muscle cell formation, EBs were plated at day 3 and mRNAs were analyzed at days 0, 3, 5, and 7 of differentiation by real-time RT-PCR for expression of the specific endothelial marker Tie-2 (F) and the smooth muscle marker $\alpha$-SMA (G). Results are expressed as the percentage of the expression level in control cells at day 7 and are the means \pm SEM of at least 3 independent experiments. Significance between control and treated cells is given. Color images available online at www.liebertonline.com/scd 
A

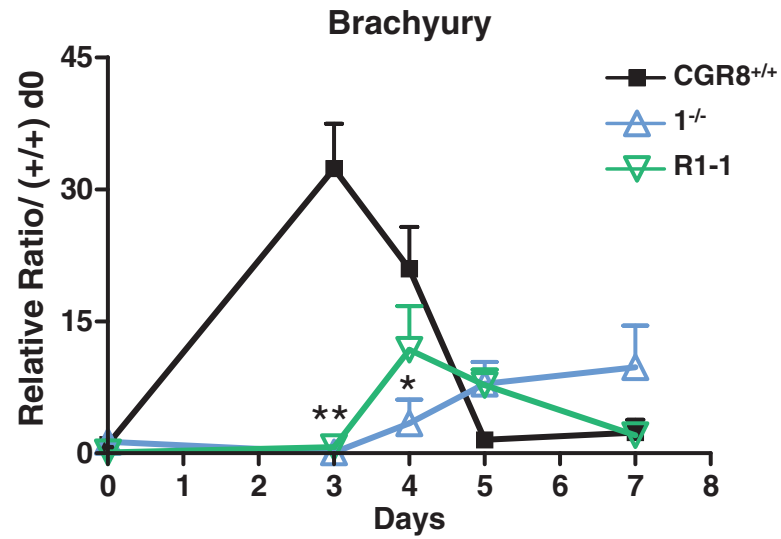

B

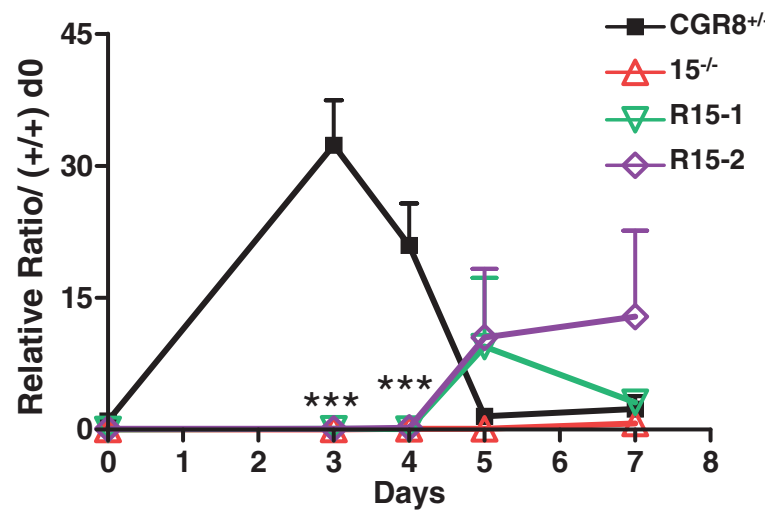

C

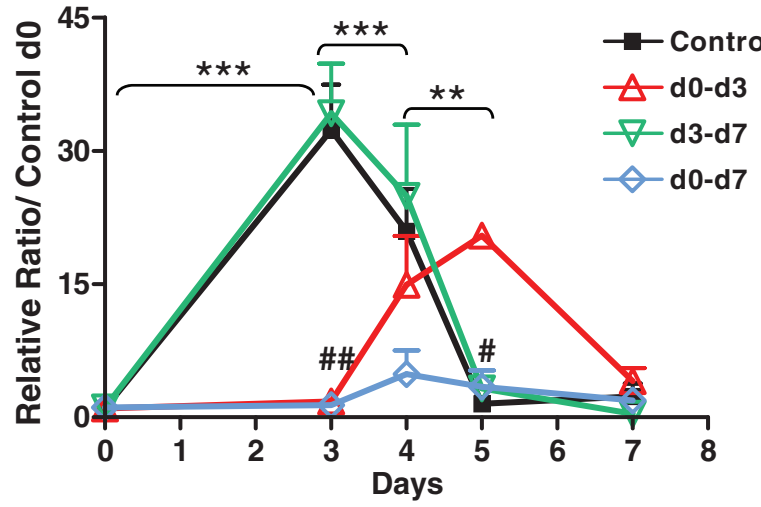

FIG. 8. The Brachyury gene expression is regulated by p38MAPK during ES cell differentiation. In (A and B), EBs from wt CGR8, $1^{-/-}$, R1-1, 15 ${ }^{-/}$, R15-1, and R15-2 ES cells were plated on gelatin at day 3 until day 7 of differentiation. Similarly, EBs from wt CGR8 ES cells were induced to differentiate in the presence or absence of PD169316 for different periods as indicated in Fig. 6A (C). mRNAs were analyzed at days $0,3,4,5$, and 7 by real-time RT-PCR for Brachyury expression. Results are expressed in arbitrary units, with the values of wt CGR8 at day 0 taken as 1, and are the means SEM of at least 3 independent experiments. *Significance between wt and $\mathrm{KO}$ cells $(\mathbf{A}, \mathbf{B})$ or between day 0 versus day 3 , day 3 versus day 4 , and day 4 versus day 5 (C). ${ }^{*} P<0.05$, ${ }^{* *} P<0.01$, and ${ }^{* * *} P<0.001$. "Significance between control and treated cells (C). ${ }^{\#} P<0.05$ and ${ }^{\# \#} P<0.01$. Color images available online at www.liebertonline.com/scd
There is an abundant literature showing that p38MAPK activity increased during myoblast differentiation and that this pathway regulates the expression of muscle-specific genes via the control of MyoD and MEF2 muscle-specific transcription factors (for review, see [41]). In vivo, p38MAPK is involved in the developing somite myotome of mice [42]. The p38 MAPK pathway is required for the activation of the quiescent muscle precursor, the satellite cell [43], whereas neither the ERK nor the JNK pathway is involved in the skeletal myogenic process [44,45]. Importantly, myoblasts lacking p38 $\alpha$ are unable to differentiate and to form multinucleated myotubes [46]. Our study extends the requirement of p38MAPK in skeletal myogenesis to the early embryonic events of this process. Particularly, analysis of muscle differentiation capacities of either p38 $\alpha$ KO ES cells or wt ES cells treated by the $\mathrm{p} 38$ inhibitor demonstrated that this pathway is required continuously between days 0 and 5 for skeletal myogenesis.

Altogether our results demonstrate that the p38MAPK activity is required continuously between days 0 and 5 for cardiac, endothelial, smooth muscle, and skeletal muscle mesodermal commitment and, conversely, inhibits neurogenesis. We were able to dissect this requirement into 2 successive steps: the first one between days 0 and 3 corresponds to basal p38 activity necessary for the formation of endothelial, smooth muscle, and skeletal muscle lineages and correlates with regulation of Brachyury expression, whereas the second step corresponds to the spontaneous peak of p38MAPK activity between days 3 and 5 [16]; in addition to the former mesodermal lineages, cardiomyogenesis is controlled at this step.

Owing to the known biological role of Brachyury and the effect of p38MAPK inhibition on the expression of this gene, one can hypothesize that the $\mathrm{d} 0-\mathrm{d} 3$ p38MAPK biological function in ES commitment is mediated by Brachyury. However, the reexpressing cell lines, although rescuing the mesodermal defects displayed by p38MAPK KO ES cells, do not recapitulate wt Brachyury expression, suggesting that this gene is not involved in this p38MAPK function. Importantly, it is noteworthy that the mesodermal rescues and the reexpressed p38MAPK protein levels are partial. Therefore, it is possible that the peak of Brachyury expression at day 3 requires wt p38MAPK levels and, in turn, that this peak is necessary for the full mesodermal response of ES cells. Further works on Brachyury regulation are necessary to decipher the molecular links between p38MAPK, Brachyury, and mesodermal commitment of ES cells.

Regarding the control of mouse ES cell differentiation, it is noteworthy that the p38MAPK pathway displays unique biological properties when compared with ERK and JNK MAPK pathways. Indeed, we found that p38MAPK constitutes a major switch between mesodermal lineages (p38 on) and neurogenesis (p38 off), whereas the ERK pathway plays a different control earlier, because ERK2 KO cells are blocked in both mesodermal and neuronal differentiations [47], and JNK is involved only in neurogenesis [48].

Owing to the fact that p38MAPK pathway controls ES cell commitment toward mesodermal lineages, our results suggest that the precise modulation of this pathway early on during ES cell differentiation would help their use in regenerative medicine by improving the efficiency of differentiation into specific lineages. 


\section{Acknowledgments}

The authors thank Drs. B.P. Sleckman and David Engelberg for providing the p38 KO ES cell lines and p38 cDNA clones, respectively. This work was supported by a grant from the Association Française contre les Myopathies. E.B. was supported by fellowships from the Groupe d'Eude sur l'Hémostase et la Thrombose and the Fondation pour la Recherche Médicale. O.H. was supported by a fellowship from the Association Française contre les Myopathies.

\section{Author Disclosure Statement}

No competing financial interests exist.

\section{References}

1. Kashyap V, N Rezende, K Scotland, S Shaffer, J Persson, L Gudas and N Mongan. (2009). Regulation of stem cell pluripotency and differentiation involves a mutual regulatory circuit of the NANOG, OCT4, and SOX2 pluripotency transcription factors with polycomb repressive complexes and stem cell microRNAs. Stem Cell Dev 18:1093-1108.

2. Wobus AM. (2001). Potential of embryonic stem cells. Mol Aspects Med 22:149-164.

3. Wobus AM and KR Boheler. (2005). Embryonic stem cells: prospects for developmental biology and cell therapy. Physiol Rev 85:635-678.

4. Rohwedel J, K Guan and AM Wobus. (1999). Induction of cellular differentiation by retinoic acid in vitro. Cells Tissues Organs 165:190-202.

5. Ying Q-L, M Stavridis, D Griffiths, M Li and A Smith. (2003). Conversion of embryonic stem cells into neuroectodermal precursors in adherent monoculture. 21:183-186.

6. Dani C, AG Smith, S Dessolin, P Leroy, L Staccini, P Villageois, C Darimont and G Ailhaud. (1997). Differentiation of embryonic stem cells into adipocytes in vitro. J Cell Sci 110: 1279-1285.

7. Hescheler J, BK Fleischmann, M Wartenberg, W Bloch, E Kolossov, G Ji, K Addicks and H Sauer. (1999). Establishment of ionic channels and signalling cascades in the embryonic stem cell-derived primitive endoderm and cardiovascular system. Cells Tissues Organs 165:153-164.

8. Pearson G, F Robinson, T Beers Gibson, BE Xu, M Karandikar, K Berman and MH Cobb. (2001). Mitogen-activated protein (MAP) kinase pathways: regulation and physiological functions. Endocr Rev 22:153-183.

9. Cuenda A and S Rousseau. (2007). p38 MAP-Kinases pathway regulation, function and role in human diseases. Biochim Biophys Acta-Mol Cell Res 1773:1358-1375.

10. Morooka T and E Nishida. (1998). Requirement of p38 mitogen-activated protein kinase for neuronal differentiation in PC12 cells. J Biol Chem 273:24285-24288.

11. Rousseau S, F Houle, J Landry and J Huot. (1997). p38 MAP kinase activation by vascular endothelial growth factor mediates actin reorganization and cell migration in human endothelial cells. Oncogene 15:2169-2177.

12. Cuenda A and P Cohen. (1999). Stress-activated protein kinase-2/p38 and a rapamycin-sensitive pathway are required for C2C12 myogenesis. J Biol Chem 274:4341-4346.

13. Tamura K, T Sudo, U Senftleben, AM Dadak, R Johnson and M Karin. (2000). Requirement for p38alpha in erythropoietin expression: a role for stress kinases in erythropoiesis. Cell 102:221-231.
14. Adams RH, A Porras, G Alonso, M Jones, K Vintersten, $\mathrm{S}$ Panelli, A Valladares, L Perez, R Klein and AR Nebreda. (2000). Essential role of p38alpha MAP kinase in placental but not embryonic cardiovascular development. Mol Cell 6:109-116.

15. Allen M, L Svensson, M Roach, J Hambor, J McNeish and CA Gabel. (2000). Deficiency of the stress kinase p38alpha results in embryonic lethality: characterization of the kinase dependence of stress responses of enzyme-deficient embryonic stem cells. J Exp Med 191:859-870.

16. Aouadi M, F Bost, L Caron, K Laurent, Y Le Marchand Brustel and B Binetruy. (2006). p38 Mitogen-activated protein kinase activity commits embryonic stem cells to either neurogenesis or cardiomyogenesis. Stem Cells 24:1399-1406.

17. Bost F, L Caron, I Marchetti, C Dani, Y Le Marchand-Brustel and B Binetruy. (2002). Retinoic acid activation of the ERK pathway is required for embryonic stem cell commitment into the adipocyte lineage. Biochem J 361:621-627.

18. Kim JM, JM White, AS Shaw and BP Sleckman. (2005). MAPK p38\{alpha\} is dispensable for lymphocyte development and proliferation. I Immunol 174:1239-1244.

19. Caron L, F Bost, M Prot, P Hofman and B Binetruy. (2005). A new role for the oncogenic high-mobility group A2 transcription factor in myogenesis of embryonic stem cells. Oncogene 24:6281-6291.

20. Caron L, M Prot, M Rouleau, M Rolando, F Bost and B Binetruy. (2005). The Lac repressor provides a reversible gene expression system in undifferentiated and differentiated embryonic stem cell. Cell Mol Life Sci 62:1605-1612.

21. Dreux M, T Dao, J Fresquet, M Guerin, Z Julia, G Verney, D Durantel, F Zoulim, D Lavillette, F Cosset and B Bartosch. (2009). Receptor complementation and mutagenesis reveal SR-BI as an essential HCV entry factor and functionally imply its intra- and extra-cellular domains. PLoS Pathog 5:e1000310.

22. Nègre $D, P$ Mangeot, $G$ Duisit, $S$ Blanchard, $P$ Vidalain, $P$ Leissner, A Winter, C Rabourdin-Combe, M Mehtali, P Moullier, J Darlix and Cosset FL. (2000). Characterization of novel safe lentiviral vectors derived from simian immunodeficiency virus (SIVmac251) that efficiently transduce mature human dendritic cells. Gene Ther 7:1613-1623.

23. Murry CE and G Keller. (2008). Differentiation of embryonic stem cells to clinically relevant populations: lessons from embryonic development. Cell 132:661-680.

24. Gimond C, S Marchetti and G Pages. (2006). Differentiation of mouse embryonic stem cells into endothelial cells: genetic selection and potential use in vivo. Methods Mol Biol330:303-329.

25. Li Z, Z Wang, Y Zheng, B Xu, R Yang, D Scadden and Z Han. (2005). Kinetic expression of platelet endothelial cell adhesion molecule-1 (PECAM-1/CD31) during embryonic stem cell differentiation. J Cell Biochem 95:559-570.

26. Guo Y, J Ye and F Huang. (2007). p38alpha MAP kinasedeficient mouse embryonic stem cells can differentiate to endothelial cells, smooth muscle cells, and neurons. Dev Dyn 236:3383-3392.

27. Yamashita J, H Itoh, M Hirashima, M Ogawa, S Nishikawa, T Yurugi, M Naito, K Nakao and S-I Nishikawa. (2000). Flk1-positive cells derived from embryonic stem cells serve as vascular progenitors. Nature 408:92-96.

28. Sone M, H Itoh, J Yamashita, T Yurugi-Kobayashi, Y Suzuki, Y Kondo, A Nonoguchi, N Sawada, K Yamahara, K Miyashita, K Park, M Shibuya, S Nito, S-I Nishikawa and K Nakao. (2003). Different differentiation kinetics of vascular progenitor cells in primate and mouse embryonic stem cells. Circulation 107:2085-2088. 
29. Alexopoulou A, J Couchman and J Whiteford. (2008). The CMV early enhancer/chicken beta actin (CAG) promoter can be used to drive transgene expression during the differentiation of murine embryonic stem cells into vascular progenitors. BMC Cell Biol 9:2.

30. Showell C, O Binder and F Conlon. (2004). T-box genes in early embryogenesis. Dev Dyn 229:201-218.

31. Fehling H Jr, G Lacaud, A Kubo, M Kennedy, S Robertson, G Keller and V Kouskoff. (2003). Tracking mesoderm induction and its specification to the hemangioblast during embryonic stem cell differentiation. Development 130:4217-4227.

32. Duval D, M Malaise, B Reinhardt, C Kedinger and H Boeuf. (2004). A p38 inhibitor allows to dissociate differentiation and apoptotic processes triggered upon LIF withdrawal in mouse embryonic stem cells. Cell Death Differ 11:331-341.

33. Zheng M, C Reynolds, S-H Jo, R Wersto, Q Han and R-P Xiao. (2004). Intracellular acidosis-activated p38 MAPK signaling and its essential role in cardiomyocyte hypoxic injury 10.1096/fj.04-2607fje. FASEB J:04-2607fje.

34. Davidson SM and M Morange. (2000). Hsp25 and the p38 MAPK pathway are involved in differentiation of cardiomyocytes. Dev Biol 218:146-160.

35. Eriksson M and S Leppa. (2002). Mitogen-activated protein kinases and activator protein 1 are required for proliferation and cardiomyocyte differentiation of p19 embryonal carcinoma cells 10.1074/jbc.M107340200. J Biol Chem 277:1599216001.

36. Graichen $\mathrm{R}, \mathrm{X} X \mathrm{Xu}, \mathrm{SR}$ Braam, $\mathrm{T}$ Balakrishnan, $\mathrm{S}$ Norfiza, $\mathrm{S}$ Sieh, SY Soo, SC Tham, C Mummery, A Colman, R Zweigerdt and BP Davidson. (2008). Enhanced cardiomyogenesis of human embryonic stem cells by a small molecular inhibitor of p38 MAPK. Differentiation 76:357-370.

37. Schmidt-Lucke C, L Rossig, S Fichtlscherer, M Vasa, M Britten, U Kamper, S Dimmeler and AM Zeiher. (2005). Reduced number of circulating endothelial progenitor cells predicts future cardiovascular events: proof of concept for the clinical importance of endogenous vascular repair. Circulation 111:2981-2987.

38. Seeger FH, J Haendeler, DH Walter, U Rochwalsky, J Reinhold, C Urbich, L Rossig, A Corbaz, Y Chvatchko, AM Zeiher and S Dimmeler. (2005). p38 mitogen-activated protein kinase downregulates endothelial progenitor cells. $\underline{\text { Cir- }}$ culation 111:1184-1191.

39. Keller G. (2005). Embryonic stem cell differentiation: emergence of a new era in biology and medicine. Genes Dev 19:1129-1155.

40. Garry DJ and EN Olson. (2006). A common progenitor at the heart of development. Cell 127:1101-1104.
41. Lluis F, E Perdiguero, AR Nebreda and P Munoz-Canoves. (2006). Regulation of skeletal muscle gene expression by p38 MAP kinases. Trends Cell Biol 16:36-44.

42. de Angelis L, J Zhao, JJ Andreucci, EN Olson, G Cossu and JC McDermott. (2005). Regulation of vertebrate myotome development by the p38 MAP kinase-MEF2 signaling pathway. Dev Biol 283:171-179.

43. Jones NC, KJ Tyner, L Nibarger, HM Stanley, DDW Cornelison, YV Fedorov and BB Olwin. (2005). The p38\{alpha\}/ \{beta\} MAPK functions as a molecular switch to activate the quiescent satellite cell 10.1083/jcb.200408066. J Cell Biol 169: 105-116.

44. Jones NC, YV Fedorov, RS Rosenthal and BB Olwin. (2001). ERK1/2 is required for myoblast proliferation but is dispensable for muscle gene expression and cell fusion. I Cell Physiol 186:104-115.

45. Wu Z, PJ Woodring, KS Bhakta, K Tamura, F Wen, JR Feramisco, M Karin, JYJ Wang and PL Puri. (2000). p38 and extracellular signal-regulated kinases regulate the myogenic program at multiple steps. Mol Cell Biol 20:3951-3964.

46. Perdiguero E, V Ruiz-Bonilla, L Gresh, L Hui, E Ballestar, P Sousa-Victor, B Baeza-Raja, M Jardi, A Bosch-Comas, M Esteller, C Caelles, AL Serrano, EF Wagner and P MunozCanoves. (2007). Genetic analysis of p38 MAP kinases in myogenesis: fundamental role of p38[alpha] in abrogating myoblast proliferation. EMBO J 26:1245-1256.

47. Kunath T, MK Saba-El-Leil, M Almousailleakh, J Wray, S Meloche and A Smith. (2007). FGF stimulation of the Erk1/2 signalling cascade triggers transition of pluripotent embryonic stem cells from self-renewal to lineage commitment. Development 134:2895-2902.

48. Amura CR, L Marek, RA Winn and LE Heasley. (2005). Inhibited neurogenesis in JNK1-deficient embryonic stem cells. Mol Cell Biol 25:10791-10802.

Address correspondence to: Dr. Bernard Binetruy Inserm U626

Faculté de Médecine La Timone 27, Bd Jean Moulin 13385 Marseille Cedex 5

France

E-mail: bernard.binetruy@univmed.fr

Received for publication May 28, 2010

Accepted after revision October 18, 2010

Prepublished on Liebert Instant Online October 18, 2010 